Review

\title{
Physiological, epigenetic, and genetic regulation of vegetative phase change and rejuvenation in plants.
}

\author{
Tajbir Raihan' ${ }^{1}$, Robert Geneve², Sharyn Perry ${ }^{3}$, Carlos M. Rodriguez Lopez ${ }^{*}$
}

${ }^{1}$ Environmental Epigenetics and Genetics Group, Department of Horticulture, University of Kentucky, Lexington, KY, USA, 40546.

${ }^{2}$ Department of Horticulture, University of Kentucky, Lexington, KY, USA, 40546.

${ }^{3}$ Department of Plant and Soil Sciences, University of Kentucky, Lexington, KY, USA, 40546.

* Correspondence: Email: cmro267@uky.edu.

\begin{abstract}
In contrast to animals, adult organs in plants are not determined during embryogenesis but generated from meristematic cells as plants advance through development. Plant development involves a succession of different phenotypic stages and the transition between these stages is termed phase transition. Phase transitions need to be tightly regulated and coordinated to ensure they occur under optimal seasonal, environmental conditions. Polycarpic perennials transition through vegetative stages and the mature, reproductive stage many times during their lifecycles and, in both perennial and annual species, environmental factors and culturing methods can reverse the otherwise unidirectional vector of plant development. Epigenetic factors regulating gene expression in response to internal cues and external (environmental) stimuli influencing the plant's phenotype and development have been shown to control phase transitions. How developmental and environmental cues interact to epigenetically alter gene expression and influence these transitions are not well understood and understanding this interaction is important considering the current climate change scenarios, since epigenetic maladaptation could have catastrophic consequences for perennial plants in natural and agricultural ecosystems. Here we review studies focussing on the epigenetic regulators of the vegetative phase change and highlight how these mechanisms might act in exogenously induced plant rejuvenation and regrowth following stress.
\end{abstract}

Keywords: Rejuvenation; Phase-change, Epigenetics, Vegetative.

\section{Introduction}

Plant development is a step-by-step process causing a gradual alteration in the qualitative (germination, flowering, etc.) and quantitative (number of leaves, number of flowers, etc.) phenotype of the plant [1]. After germination and before reproduction, plants go through a vegetative growth phase when mass and photosynthetic capacity are rapidly increased. The vegetative growth phase consists of a juvenile and an adult phase that are distinguishable by unique growth patterns and structures. During the juvenile vegetative phase, plants are generally insensitive to photoperiod and floral inducers; with the transition to the adult vegetative phase, they gradually acquire reproductive competence. During vegetative growth, vegetative phase change is accompanied by species-specific changes in leaf size and shape, internode length, and trichome distribution, ultimately causing a change in the stem appearance, a condition known as heteroblasty $[2,3,4]$. Phenotypic changes associated with vegetative phase change can be subtle modifications to leaf morphology, like those observed in certain annual species (e.g., maize [5] and Arabidopsis [6], or much more dramatic changes affecting the whole structure of the shoots in perennials like Acacia, Eucalyptus and Hedera. During the reproductive phase transition, plants switch from vegetative to reproductive growth and the vegetative shoot apical meristem converts into an inflorescence meristem [7]. Most of the changes associated with 
vegetative to reproductive phase transition are unidirectional; that is, once the plant enters into the adult vegetative phase they continue forward with the reproductive phase. Perennial plants, however, alternate between the adult vegetative and the reproductive phases $[8,9]$. Most perennial species have a polycarpic growth habit, and they undergo many reproductive cycles during their lifetimes. In a perennial plant, different meristems exhibit different behaviors so that some undergo floral transition while others remain in the vegetative state $[10,11,12]$.

A secondary phase change, when a reversion from the adult to the juvenile phase occurs following pruning, grafting or tissue culture, allows plants to restore juvenile features [13]. The reversibility of phase change has led to a long-standing view that epigenetics plays a major role in its regulation [14]. In this paper, we discuss the physiological, epigenetic and genetic control of vegetative phase change and rejuvenation in plants.

\section{The role of endogenous factors in vegetative phase change and rejuvenation}

Endogenous factors have significant roles in vegetative phase change and rejuvenation. Hormones play crucial roles in the rejuvenation of trees, with cytokinins and gibberellins able to induce rejuvenation and maintain the juvenile state [15,16]. Huang et al. [17] showed that the ability to root in successive generations of cuttings of the shrub Buxussinica var. parvifoli was correlated with changes in the concentrations of hormones such as indole-3-acetic acid (IAA), abscisic acid (ABA) and gibberellin A4 (GA4). The IAA/ABA content determines the degree of the juvenile phenotype in vitro and the rooting capacity of tender stems. In annual Arabidopsis, glycine-rich RNA-binding proteins gather at different stages of rejuvenation and affect the recovery of rooting capacity which is regulated by both auxin and ABA $[18,19]$.

The effects of GA in controlling phase change depend upon the species. Exogenous GA application was found to promote rejuvenation in English ivy [20] and in Acacia melanoxylon [21] while it accelerated vegetative phase change and flowering in maize [22] and Arabidopsis [6,23]. In some perennial species, GA can cause a reversion of the reproductive phase to the vegetative phase [24]. The concentrations of IAA and ABA were found to be higher in rejuvenated shoots than in mature walnut shoots, while GA3 and zeatin-riboside (ZR) showed the opposite pattern [25]. In Sequoia sempervirens, the small RNA (sRNA) specific for the ABA biosynthesis enzyme 9-cis-epoxycarotenoid dioxygenase was found to have only a few transcripts in adult shoots and, with the maturation of the shoots, ABA content increased as much as 1000-fold, while it decreased significantly during rejuvenation [26]. Higher ABA content might be the result of sRNA regulation, transcriptional activation, or insufficient ABA turnover [26]. Moreover, three genes in Yang's cycle (in the ethylene biosynthesis cycle) were also found to be highly expressed in adult shoots compared with rejuvenated or juvenile shoots when there was no intervention by sRNAs, indicating some role of ethylene in phase transitions [26]. During root induction in plant rejuvenation, hormones are restricted to the phloem sieve and companion cells at the bottom of rejuvenated or mature soft shoots.

Rejuvenation includes restoring juvenile features like increasing esterase and peroxidase activities [27] and improving photosynthetic and respiratory rates [28]. Phase reversal is also accompanied by genomic features like a rearrangement of nuclear and mitochondrial DNA, restoration of protein phosphorylation or phosphokinase activity, DNA methylation in nuclear and mitochondrial DNA [29], reappearance of mitochondrial circular DNA molecules [30] and the recovery of sRNA expression [26]. Thus, plant rejuvenation is correlatively associated with DNA methylation, sRNA molecules, and the rearrangement of nuclear and mitochondrial DNA. 
Global changes in DNA methylation have been associated to tissue development and differentiation and organ function acquirement [31]. In the heterophyllous species Ilex aquifolium, change in leaf morphology induced by herbivory pressure, from entire adult leaves to dentate juvenile leaves, correlates with change in leaf DNA methylation profiles [32]. Callus-induced dedifferentiated cells were found to have higher levels of euchromatin (open chromatin) in comparison to differentiated cells that are richer in heterochromatin (closed chromatin) in Arabidopsis [33]. Gene expression ontology studies of in vitro culture-induced citrus callus overexpressing the microRNA miR156, identified DNA methylation processes as enriched during culture [34]. Mobile sRNAs, which have been shown to be part of a systemic signaling pathway in plants $[35,36,37,38,39]$, have also been shown to be capable of modifying the methylation profiles of the sink organs they target in many species. Taken collectively, these results indicate that multiple molecular mechanisms interact to regulate epigenetic profiles at phase transitions.

\section{Vegetative phase change control in annual species and woody perennials}

The timing of the transition between the juvenile to adult phases differs hugely depending upon the species. In annual species, this transition happens relatively soon after the completion of germination, while, in perennials, this transition might take months or years. Perennials also exhibit major morphological changes in shoot architecture before and after vegetative phase change compared to annuals. The morphological changes associated with vegetative phase change in perennials need to be temporally and spatially coordinated as these species encounter environmental constraints depending on season and many biotic and abiotic stresses during their long lifecycles [40]. In numerous studies on annuals like Arabidopsis thaliana and maize (Zea mays) the microRNAs (miRNA) miR156 and miR172 have been found to regulate phase transitions. In annual species, the expression of miR156 is very high in the seedling stage and gradually declines with the juvenileto-adult transition, while miR172 shows the opposite expression pattern. A similar miRNA expression pattern has also been observed in perennial woody species with highly characterized juvenile and adult phases like Acacia confusa, Acacia colei, Eucalyptus globulus, Hedera helix and Quercus acutissima. miR156 is common to almost all the major plant taxa and its role in the control of vegetative phase change seems to be conserved throughout the whole plant kingdom [41].

\section{4. miRNAs regulate vegetative phase change genes}

Vegetative phase change is regulated by the post-transcriptional repression of phase change genes by specific, non-coding miRNA families and these miRNA encoding genes are themselves epigenetically regulated. Increased accumulation of miR156 and miR157 delays the juvenile to adult transition, while accumulation of miR172 accelerates this transition $[42,43]$. Although phenotypic alterations associated with vegetative phase transition are very distinct between annual and perennial plants, vegetative phase change in both is controlled by the same miRNA families.

In annual plants such as maize and Arabidopsis, molecular genetic analyses showed that miR156 plays a crucial role [44,45]. During the juvenile phase, the expression of miR156 is elevated then declines during vegetative phase change. The overexpression of miR156 extends the expression of juvenile traits such as juvenile leaf characters, higher leaf initiation rates, increased branching density, and flowering delay, while plants where miR156 is suppressed show opposite phenotypes [42]. The targets of miR156 are SQUAMOSA PROMOTER BINDING PROTEIN-like (SBP/SPL) genes $[46,47,48]$. SPL is a plant-specific transcription factor family, first discovered in Antirrhinum majus by Klein et al. [49], that exists in all plant taxa studied. Many SBP/SPL genes are regulated by miR156 [50,51,52] 
and miR156 -regulated SPL genes are believed to control similar sets of traits in different plant species, as the phenotypes of the plants overexpressing miR156-encoding genes are almost identical in all species studied $[44,51,45,53]$. SPL transcription factors vary in size, ranging from 100 to 927 amino acids in A. thaliana [54], and include an evolutionarily conserved DNA binding domain that is around 76 amino acids long [50]. They regulate many important parts of a plant's life cycle including vegetative phase change, inflorescence architecture, fruit development, grain morphology, leaf initiation, and pollen development [55,56]. SPL genes in A. thaliana carry a miR156 microRNA response element within their 3'-UTR region that is highly complementary to miR156 (Rhoades et al., 2002). miR156 causes transcriptional repression through cleavage of $S P L$ transcripts, resulting in reduced SPL mRNA levels [45,51]. As miR156 levels decrease with aging, this leads to an increase in SPL transcripts.

miR172 is also known for its involvement in vegetative phase change and flowering and was first identified in Arabidopsis [57]. miR172 targets the mRNA of many transcription factors associated with the APETALA2 (AP2)-like protein, including Glossy15 (GL15) in maize [58]. The GL15 transcription factor maintains the juvenile state, increasing the number of juvenile leaves and delaying the flowering process. $m i R 172$ regulates the phase transition by cleavage and negative regulation of GL15 [58]. miR172 levels start to increase after germination and continue to increase gradually with plant maturation, the opposite of the miR156 expression pattern. Overexpression of miR156 extends the expression of juvenile vegetative traits and delays flowering [44,45], whereas the overexpression of miR172 accelerates flowering [59,60,61]. miR156 negatively regulates miR172 activity [62] by targeting SPL transcription factors which are positive regulators of $m i R 172$ expression [42,63]. As the plant matures and miR156 transcription declines, higher levels of miR172 eventually lead to the downregulation of GL15 [58]. Overexpression of miR156 in the perennial Populus $x$ canadensis also downregulated the expression of SPL genes and miR172 and extended the juvenile phase [41].

\section{The influence of histone modifications in phase transition}

The miR156/157-SPL pathway is the master regulator of vegetative phase change in plants, and the genes that are associated with this pathway undergo epigenetic regulation via histone modification and chromatin remodeling. Alteration of chromatin structure is a prerequisite for the downregulation of MIR156A and MIR156C and the expression of genes encoding these miRNAs is regulated by the chromatin modification polycomb repression complex 2 (PRC2)-mediated histone H3 lysine 27 trimethylation (H3K27me3). H3K27me3 is a repressive chromatin mark and a major silencing mechanism in plants with a crucial role in regulating the timing of developmental phase transitions [64,65,66]. It downregulates embryonic genes from the roots and shoots and represses SHOOTMERISTEMLESS (STM) in leaves. H3K27me3 also has a contribution in controlling flowering time by preventing the early expression of floral genes [67] and repressing FLOWERING LOCUS C $(F L C)$. Whole-genome analysis showed that there are thousands of loci in the $A$. thaliana genome carrying the H3K27me3 mark catalyzed by the PRC2 complex [68,69]. Many MIR156/157 loci (specifically the dominant loci MIR156A, MIR156C, and MIR157A) have H3K27me3 marks. SPL genes responsible for juvenile-to-adult transition lack the H3K27me3 mark, suggesting that PRC2 promotes the transcription of the SPL genes by suppressing the transcription of MIR156/157 loci [69]. During vegetative phase change, the reduction in overall transcription of MIR156A and MIR156C loci is due to an increase in binding of the PRC2 complex which ultimately leads to an increase in the H3K27me3 mark in their promoters and transcribed regions and a decrease in the H3K27 acetylation mark close to transcription start sites [70]. Mutations in the chromatin-remodeling complex 
SWR1 and the genes encoding H2A.Z also cause a significant reduction in the expression of MIR156A and MIR156C which leads to the acceleration of vegetative phase change. H2A.Z promotes MIR156A and MIR156C expression in the early, juvenile stage by aiding the deposition of an alternative lysine methylation mark, H3K4me3 [70]. In each generation, the miR156/157 silencing mechanism is reset back to the active state [71].

\section{The reversibility of phase change - rejuvenation and regrowth}

Under certain circumstances phase change is reversible. This secondary phase change, when plants go back from the adult phase to the juvenile phase and shoot meristems attain juvenility, is also known as rejuvenation [72] and this process enables plants to regain juvenile physiological features. Plant rejuvenation can be achieved through severe pruning, in vitro tissue culture and in vitro repetitive grafting of mature shoot tips onto juvenile rootstocks. miR156, the master regulator of vegetative phase change, also appears to have a crucial role in plant rejuvenation events. Studies on in vitro maize culture showed that miR156 levels are significantly increased in adult shoot apices [73] and the expression of $S P L$ genes was found to be significantly lower in rejuvenating maize shoots [74], indicating that the miR156-SPL pathway plays a role in rejuvenation.

The role of sRNA was also studied in juvenile, adult and rejuvenating S. sempervirens, where expression profiling and target gene prediction identified some unique sRNAs with possible functions in controlling photosynthesis and rooting competence during plant rejuvenation [26]. An increase in SsmiR156 and a decrease in SsmiR172 was found in the rejuvenating plants, indicating their roles in reversing vegetative phase change. These results suggested that both juvenile and rejuvenated stages of $S$. sempervirens were being regulated by a similar miRNA regulatory mechanism [26].

\section{Environment-epigenetic interactions regulating phase transition and regrowth}

Plants must constantly adapt to changing environmental conditions to survive and they have sophisticated mechanisms to regulate important genes in response to environmental fluctuations. Plants can sense environmental signals and transmit those signals using signal transduction. This triggers a cascade of chemical reactions and the accumulation of required transcription factors that activate the genes necessary for survival and adaptation [75].

Under abiotic stress, one important strategy that plants use to survive and adapt is controlling phase transition to either prolong or shorten the length of their juvenile phase and adjust their flowering time. In unfavorable environmental conditions such as salt or drought stress [76] or phosphate starvation [77], the expression of miR156-encoding genes is induced to maintain the juvenile phase of the plant for a comparatively longer period. When the environment returns to favorable conditions, miR156 is suppressed to accelerate the vegetative phase transition [76]. Under UV-B radiation, miR156 is upregulated by the reduction in PRC2 -mediated H3K27me3 modification at MIR156A/MIR156C loci, similarly resulting in a delay in vegetative phase change [78] (Fig 1). In elevated $\mathrm{CO}_{2}$ concentrations that are favorable for plant growth, miR156 and miR157 transcripts decrease, miR172 increases, several SPL genes are upregulated and the transition to flowering is accelerated [79]. In high temperature stress, however, although miR156/miR157 expression increases and miR172 expression is downregulated, SPL responses are mixed, with only transient downregulation, and flowering time is advanced $[79,80]$. Nonetheless, acquired thermotolerance in $A$. thaliana - when plants have heat stress memory and improved tolerance of 
a recurring heat stress - was shown to depend on this regulation of miR156-SPL expression during the first exposure [80]. Thus, the miR156-SPL module has been shown to regulate stress tolerance and control the vegetative phase transition in response to environmental stress, mediated by reversible epigenetic modifications (Fig 1).

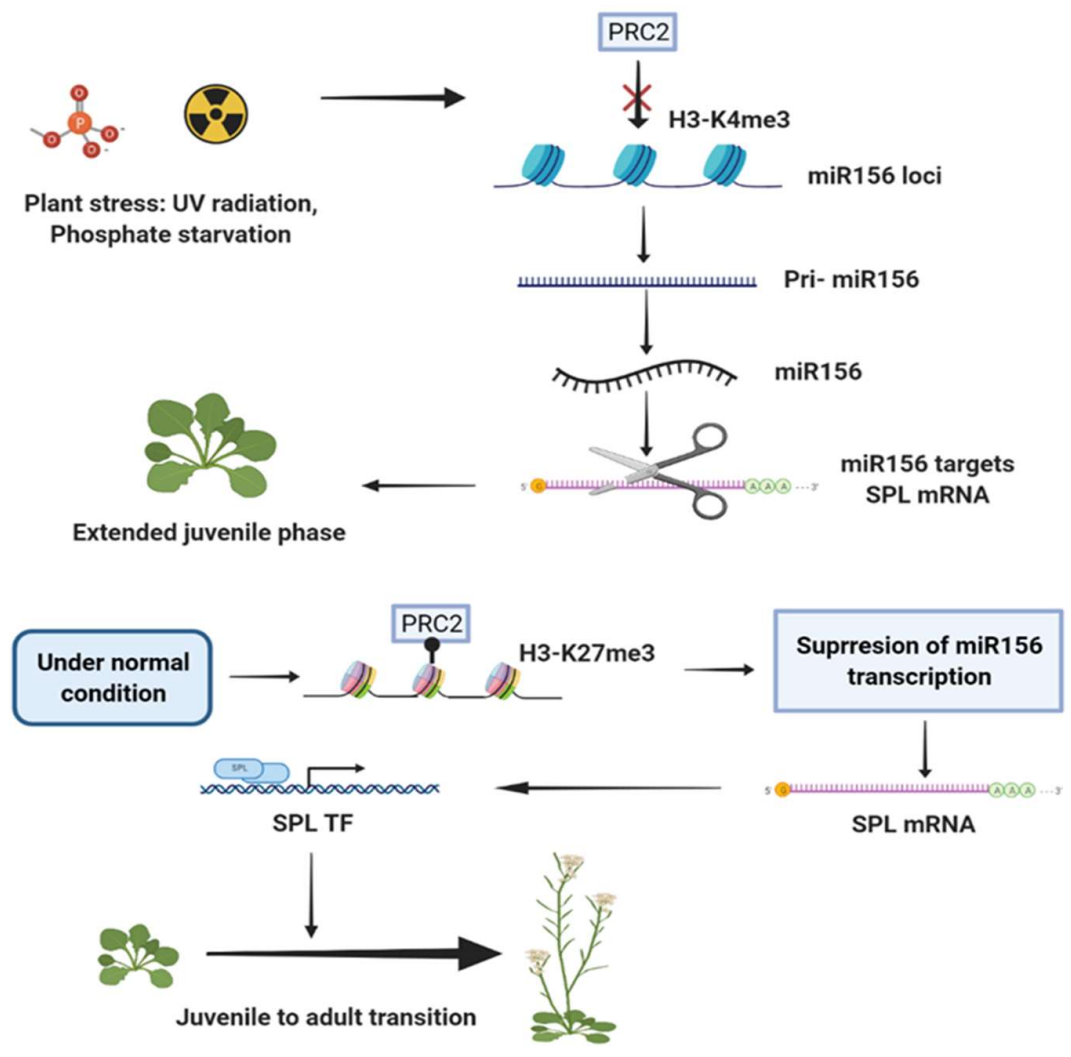

Figure 1. Proposed model for environment-epigenetic interactions regulating phase transition. Under normal conditions, PRC2-mediated H3K27me3 modification suppresses miR156 transcription influencing the transition from juvenile to adult phase. Under stresses such as salinity, drought, UV-B radiation and phosphate starvation, plants experience an extended juvenile phase because of a reduction in PRC2-mediated H3K27me3 modification at MIR156A/MIR156C loci.

Sometimes plants are exposed to extreme stresses, like browsing or fire, which result in severe damage to the crown tissue or above-ground parts. Despite after-fire events giving the surviving plants a "window of opportunity" for regeneration when they do not have to compete for the resources, such as light, nutrients, and water [81], a huge number of plants are killed by the total defoliation caused by fire, and only a few of them show the capacity to re-sprout [82]. Re-sprouting can start from above- or below-ground tissues depending on the number and location of dormant buds [83]. Depending on the ecosystem and species, a new plant can emerge after the crown damage of the mother plant from structures like roots, rhizomes, tubers, lignotubers or corms. Because of the excellent heat insulating capacity of the soil, these bud-bearing, below-ground structures provide fitness benefits in a fire-prone ecosystem.

Regrowth can also begin from above-ground structures like epicormic buds, one type of developmentally arrested, accessory meristem. In a normal situation, their growth is 
suppressed hormonally, but they are capable of becoming active shoots when the primary shoots are damaged or decapitated $[84,85]$. Whole plants are able to re-sprout and regrow from these arrested buds that have previously been held in a fixed, juvenile state.

Eucalyptus trees are best known for their ability to regenerate branches vegetatively from epicormic buds along their trunks. Epicormic buds of Eucalyptus are located much deeper in the bark than in most species, at the level of vascular cambium, and are therefore more protected from fire damage [82]. Epicormic buds remain in an arrested state when the shoot undergoes phase change, indicating that accessory meristems like epicormic buds do not have the innate timing responses of apical meristems and that they are influenced by the status of the whole plant [84].

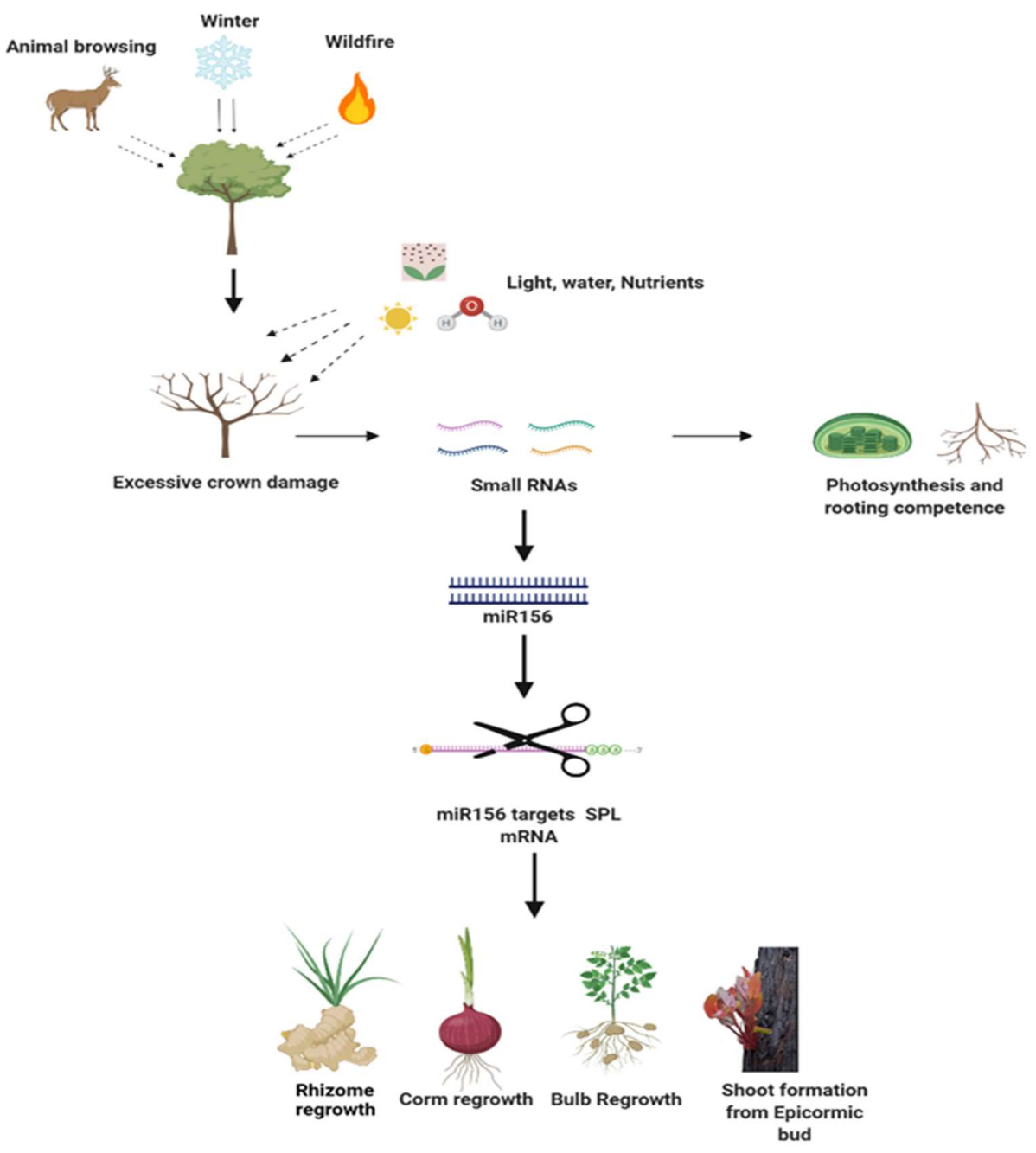

Figure 2. Proposed model for the role of miRNA156 in plant re-sprouting following stress. Plants can experience excessive crown damage due to extreme seasonal changes (e.g., winter), animal browsing or wildfire. They may regain their photosynthetic tissues and rooting capacity by the actions of a unique set of small RNAs. The function of miR156 in rejuvenated shoots is identical to in juvenile shoots where they target SPL mRNAs for post-transcriptional degradation. Similarly, the miR156-SPL pathway might be in action in the case of regrowth or re-sprouting following stress. 
In annual $A$. thaliana, miR156-targeted SPL controls both shoot regeneration [86] and root meristem activity that determines root-derived de novo shoot regeneration [87] in an age-dependent manner. A comparative physiological and molecular analysis between perennial Arabis alpina and annual A. thaliana also showed that differential expression of miR156 determined the polycarpic perenniality in A. Alpina [88]. These findings, together with the conserved molecular pathway for rejuvenation in woody perennials and annuals, suggest that the miR156-SPL pathway, which is in action during plant rejuvenation, might also influence plant regrowth and re-sprouting capacity following severe damage (a schematic representation of this concept is depicted in Fig 2). However, further studies comparing plant rejuvenation and plant resprouting are required to understand their similarities and differences.

\section{Future directions}

Although much is known about the physiology, genetics, and epigenetics of vegetative phase change, there are many long-standing questions about both vegetative phase change and rejuvenation which remain to be answered. Phase transition is associated with changes in miRNA expression, but how plants detect the correct developmental phase is unknown. The source and the identity of the signals that initiate this transition and are still elusive. Recent studies have shown that the miRNA families that control vegetative phase change in annuals are also responsible for phase transitions in perennials. In perennials, vegetative phase change is associated with dramatic changes in shoot architecture, while only minor phenotypic changes occur in annuals, and it is not known why perennials have more distinct juvenile and adult phase phenotypes compared with annuals despite being regulated by the same mechanisms. The expression patterns of miR156 and miR157 are similar in rejuvenated and in juvenile shoots [73] but this proposed similarity is still quite obscure and more comparative studies between these two stages are required to assess how identical they are. Many of these questions may best be answered by using epigenetic analyses as tools to study vegetative phase change and rejuvenation in both annual and perennial systems. Such analyses could help to detect the source and identity of the signals initiating phase change. All the epigenetic features (DNA methylation in nuclear and mitochondrial DNA, sRNA molecules, and rearrangement of nuclear and mitochondrial DNA) associated with vegetative phase reversal $[29,30,26]$ indicate that they are synchronized to maintain epigenetic memory during vegetative propagation. Further studies are needed to unravel the molecular mechanisms of epigenetic memory which will not only aid our understanding of plant rejuvenation and phase transitions but can also be utilized as a tool to allow breeders, nurseries, and growers to maintain favorable traits during clonal propagation.

Author Contributions: Conceptualization, T.R. and C.M.R.-L.; investigation, T.R. and C.M.R.-L.; writing-original draft preparation, T.R. and C.M.R.-L.; funding acquisition, C.M.R.-L. All authors have read and agreed to the published version of the manuscript.

Funding: CMRL is partially supported by the National Institute of Food and Agriculture, AFRI Competitive Grant Program Accession number 1018617 and National Institute of Food and Agriculture, United States Department of Agriculture, Hatch Program accession number 1020852.

Institutional Review Board Statement: Not applicable.

Informed Consent Statement: Not applicable.

Data Availability Statement: Not applicable.

Conflicts of Interest: The authors declare no conflict of interest. 


\section{References}

1. Gatsuk, L.; Смирнова, O.; Vorontzova, L.; Zaugolnova, L. Zhukova, L.; Smirnova, L.; Vorontzova, L.; Zaugolnova, L.; Ztiukova, Age States of Plants of Various Growth Forms: A Review AGE STATES OF PLANTS OF VARIOUS GROWTH FORMS: A REVIEW. The Journal of Ecology 1980, 68, 675-696.

2. Poethig, R. S., Phase Change and the Regulation of Shoot Morphogenesis in Plants. Science 1990, 250 (4983), $923-930$.

3. Poethig, R. S., The Past, Present, and Future of Vegetative Phase Change. Plant Physiology 2010, 154 (2), $541-544$.

4. Zotz, G.; Wilhelm, K.; Becker, A., Heteroblasty-A Review. The Botanical Review 2011, 77, 109-151.

5. Poethig, S., A non-cell-autonomous mutation regulating juvenility in maize. Nature 1988, 336 (6194), 82-83.

6. Telfer, A.; Bollman, K. M.; Poethig, R. S., Phase change and the regulation of trichome distribution in Arabidopsis thaliana. Development 1997, 124 (3), 645-654.

7. Adrian, J.; Torti, S.; Turck, F., From Decision to Commitment: The Molecular Memory of Flowering. Molecular Plant 2009, 2 (4), 628-642.

8. Wareing, P. F., Problems of juvenility and flowering in trees. Journal of the Linnean Society of London, Botany 1959, 56 (366), 282289.

9. Brink, R. A., Phase Change in Higher Plants and Somatic Cell Heredity. The Quarterly Review of Biology 1962, 37 (1), 1-22.

10. Battey, N. H.; Tooke, F., Molecular control and variation in the floral transition. Current Opinion in Plant Biology 2002, 5 (1), 6268.

11. Amasino, R., Floral induction and monocarpic versuspolycarpic life histories. Genome Biology 2009, 10 (7), 228.

12. Albani, M. C.; Coupland, G., Chapter Eleven - Comparative Analysis of Flowering in Annual and Perennial Plants. In Current Topics in Developmental Biology, Timmermans, M. C. P., Ed. Academic Press: 2010; Vol. 91, pp 323-348.

13. Liu, W. Y.; Chang, Y. M.; Chen, S. C.; Lu, C. H.; Wu, Y. H.; Lu, M. Y.; Chen, D. R.; Shih, A. C.; Sheue, C. R.; Huang, H. C.; Yu, C. P.; Lin, H. H.; Shiu, S. H.; Ku, M. S.; Li, W. H., Anatomical and transcriptional dynamics of maize embryonic leaves during seed germination. Proc Natl Acad Sci U S A 2013, 110 (10), 3979-84.

14. Greenwood, M.; Hutchison, K. In Maturation as a Developmental Process, 1993.

15. Ford, Y. Y.; Taylor, J. M.; Blake, P. S.; Marks, T. R., Gibberellin A3 stimulates adventitious rooting of cuttings from cherry (Prunus avium). Plant Growth Regulation 2002, 37 (2), 127-133.

16. Perrin, Y.; Patrick, D.; Ladders, L.; Carrons, M.-P., Endogenous cytokinins as biochemical markers of rubber-tree (Hevea brasiliensis) clone rejuvenation. Plant Cell, Tissue and Organ Culture 1997, 47, 239-245.

17. Huang, Y.; Ji, K.-s.; Zhai, J.-r., Relationship between rooting ability and endogenous phytohormone changes in successive continuous generation cuttings of Buxus sinica var. parvifolia, an endangered woody species in China. Forestry Studies in China 2007, 9 (3), 189-197.

18. Kim, J. S.; Jung, H. J.; Lee, H. J.; Kim, K. A.; Goh, C.-H.; Woo, Y.; Oh, S. H.; Han, Y. S.; Kang, H., Glycine-rich RNA-binding protein7 affects abiotic stress responses by regulating stomata opening and closing in Arabidopsis thaliana. The Plant Journal 2008, 55 (3), 455-466.

19. Kim, J. Y.; Kim, W. Y.; Kwak, K. J.; Oh, S. H.; Han, Y. S.; Kang, H., Glycine-rich RNA-binding proteins are functionally conserved in Arabidopsis thaliana and Oryza sativa during cold adaptation process. Journal of experimental botany 2010, 61 (9), $2317-2325$.

20. Rogler, C. E.; Hackett, W. P., Phase change in Hedera helix: stabilization of the mature form with abscisic acid and growth retardants. Physiologia Plantarum 1975, 34 (2), 148-152.

21. Borchert, R., Gibberellic acid and rejuvenation of apical meristems in acacia melanoxylon. Naturwissenschaften 1965, 52 (3), 6566.

22. Evans, M.; Poethig, R. S., Gibberellins Promote Vegetative Phase Change and Reproductive Maturity in Maize. Plant Physiology 1995, 108 (2), 475-487.

23. Wilson, R. N.; Heckman, J. W.; Somerville, C. R., Gibberellin Is Required for Flowering in Arabidopsis thaliana under Short Days. Plant Physiology 1992, 100 (1), 403-408.

24. Zimmerman, R. H.; Hackett, W. P.; Pharis, R. P., Hormonal Aspects of Phase Change and Precocious Flowering. In Hormonal Regulation of Development III: Role of Environmental Factors, Pharis, R. P.; Reid, D. M., Eds. Springer Berlin Heidelberg: Berlin, Heidelberg, 1985; pp 79-115.

25. Liu, H.; Gao, Y.; Song, X.; Ma, Q.; Zhang, J.; Pei, D., A novel rejuvenation approach to induce endohormones and improve rhizogenesis in mature Juglans tree. Plant methods 2018, 14, 13-13.

26. Chen, Y.-T.; Shen, C.-H.; Lin, W.-D.; Chu, H.-A.; Huang, B.-L.; Kuo, C.-I.; Yeh, K.-W.; Huang, L.-C.; Chang, I.-F., Small RNAs of Sequoia sempervirens during rejuvenation and phase change. Plant Biology 2013, 15 (1), 27-36.

27. Huang, H.-j.; Chen, Y.; Kuo, J.-L.; Kuo, T.-t.; Tzeng, C.-c.; Huang, B.-l.; Chen, C.-m.; Huang, L.-c., Rejuvenation of Sequoia sempervirens in Vitro: Changes in Isoesterases and Isoperoxidases. Plant and Cell Physiology 1996, 37 (1), 77-80.

28. Huang, L.-C.; Chow, T.-Y.; Tseng, T.-C.; Kuo, C.-I.; Liu, S.-M.; Ngoh, M.-G.; Murashige, T.; Huang, H.-J., Association of mitochondrial plasmids with rejuvenation of the coastal redwood, Sequoia sempervirens (D. Don) Endl. Botanical Bulletin of Academia Sinica 2003, 44 .

29. Huang, L.-C.; Hsiao, L.-J.; Pu, S.-Y.; Kuo, C.-I.; Huang, B.-L.; Tseng, T.-C.; Huang, H.-J.; Chen, Y.-T., DNA methylation and genome rearrangement characteristics of phase change in cultured shoots of Sequoia sempervirens. Physiologia Plantarum 2012, 145 (2), 360-368. 
30. Huang, L.-C.; Lin, L.-Y.; Chen, C.-M.; Chen, L.-J.; Huang, B.-L.; Murashige, T., Phase reversal in Sequoia sempervirens in relation to mtDNA. Physiologia Plantarum 1995, 94 (3), 379-383.

31. Konate, M.; Wilkinson, M. J.; Taylor, J.; Scott, E. S.; Berger, B.; Rodriguez Lopez, C. M., Greenhouse Spatial Effects Detected in the Barley (Hordeum vulgare L.) Epigenome Underlie Stochasticity of DNA Methylation. Frontiers in Plant Science 2020, 11 (1398).

32. Herrera, C. M.; Bazaga, P., Epigenetic correlates of plant phenotypic plasticity: DNA methylation differs between prickly and nonprickly leaves in heterophyllous Ilex aquifolium (Aquifoliaceae) trees. Botanical Journal of the Linnean Society 2013, 171 (3), 441-452.

33. Lee, K.; Park, O. S.; Jung, S. J.; Seo, P. J., Histone deacetylation-mediated cellular dedifferentiation in Arabidopsis. J Plant Physiol 2016, 191, 95-100.

34. Long, J.-M.; Liu, C.-Y.; Feng, M.-Q.; Liu, Y.; Wu, X.-M.; Guo, W.-W., miR156-SPL modules regulate induction of somatic embryogenesis in citrus callus. Journal of Experimental Botany 2018, 69 (12), 2979-2993.

35. Yoo, B.-C.; Kragler, F.; Varkonyi-Gasic, E.; Haywood, V.; Archer-Evans, S.; Lee, Y. M.; Lough, T. J.; Lucas, W. J., A Systemic Small RNA Signaling System in Plants. The Plant Cell 2004, 16 (8), 1979-2000.

36. Buhtz, A.; Pieritz, J.; Springer, F.; Kehr, J., Phloem small RNAs, nutrient stress responses, and systemic mobility. BMC Plant Biology 2010, 10 (1), 64.

37. Huen, A. K.; Rodriguez-Medina, C.; Ho, A. Y. Y.; Atkins, C. A.; Smith, P. M. C., Long-distance movement of phosphate starvation-responsive microRNAs in Arabidopsis. Plant Biology 2017, 19 (4), 643-649.

38. Pant, B. D.; Buhtz, A.; Kehr, J.; Scheible, W.-R., MicroRNA399 is a long-distance signal for the regulation of plant phosphate homeostasis. The Plant journal: for cell and molecular biology 2008, 53 (5), 731-738.

39. Molnar, A.; Melnyk, C. W.; Bassett, A.; Hardcastle, T. J.; Dunn, R.; Baulcombe, D. C., Small Silencing RNAs in Plants Are Mobile and Direct Epigenetic Modification in Recipient Cells. Science 2010, 328 (5980), 872-875.

40. Ahsan, M. U.; Hayward, A.; Irihimovitch, V.; Fletcher, S.; Tanurdzic, M.; Pocock, A.; Beveridge, C. A.; Mitter, N., Juvenility and Vegetative Phase Transition in Tropical/Subtropical Tree Crops. Frontiers in Plant Science 2019, 10 (729).

41. Wang, J.-W.; Park, M. Y.; Wang, L.-J.; Koo, Y.; Chen, X.-Y.; Weigel, D.; Poethig, R. S., MiRNA Control of Vegetative Phase Change in Trees. PLOS Genetics 2011, 7 (2), e1002012.

42. Wu, G.; Park, M. Y.; Conway, S. R.; Wang, J.-W.; Weigel, D.; Poethig, R. S., The Sequential Action of miR156 and miR172 Regulates Developmental Timing in Arabidopsis. Cell 2009, 138 (4), 750-759.

43. Xu, Y.; Zhang, L.; Wu, G., Epigenetic Regulation of Juvenile-to-Adult Transition in Plants. Front Plant Sci 2018, 9, 1048.

44. Wu, G.; Poethig, R. S., Temporal regulation of shoot development in Arabidopsis thaliana by miR156 and its target SPL3. Development 2006, 133 (18), 3539-3547.

45. Chuck, G.; Cigan, A. M.; Saeteurn, K.; Hake, S., The heterochronic maize mutant Corngrass1 results from overexpression of a tandem microRNA. Nature Genetics 2007, 39 (4), 544-549.

46. Rhoades, M. W.; Reinhart, B. J.; Lim, L. P.; Burge, C. B.; Bartel, B.; Bartel, D. P., Prediction of Plant MicroRNA Targets. Cell 2002, $110(4), 513-520$.

47. Schwab, R.; Palatnik, J. F.; Riester, M.; Schommer, C.; Schmid, M.; Weigel, D., Specific Effects of MicroRNAs on the Plant Transcriptome. Developmental Cell 2005, 8 (4), 517-527.

48. Guo, A.-Y.; Zhu, Q.-H.; Gu, X.; Ge, S.; Yang, J.; Luo, J., Genome-wide identification and evolutionary analysis of the plant specific SBP-box transcription factor family. Gene 2008, 418 (1), 1-8.

49. Klein, J.; Saedler, H.; Huijser, P., A new family of DNA binding proteins includes putative transcriptional regulators of theAntirrhinum majus floral meristem identity geneSQUAMOSA. Molecular and General Genetics MGG 1996, 250 (1), 7-16.

50. Cardon, G.; Höhmann, S.; Klein, J.; Nettesheim, K.; Saedler, H.; Huijser, P., Molecular characterisation of the Arabidopsis SBPbox genes. Gene 1999, 237 (1), 91-104.

51. Xie, K.; Wu, C.; Xiong, L., Genomic Organization, Differential Expression, and Interaction of SQUAMOSA Promoter-BindingLike Transcription Factors and microRNA156 in Rice. Plant Physiology 2006, 142 (1), 280-293.

52. Riese, M.; Höhmann, S.; Saedler, H.; Münster, T.; Huijser, P., Comparative analysis of the SBP-box gene families in P. patens and seed plants. Gene 2007, 401 (1), 28-37.

53. Wang, J.-W.; Czech, B.; Weigel, D., miR156-Regulated SPL Transcription Factors Define an Endogenous Flowering Pathway in Arabidopsis thaliana. Cell 2009, 138 (4), 738-749.

54. Yang, Z.; Wang, X.; Gu, S.; Hu, Z.; Xu, H.; Xu, C., Comparative study of SBP-box gene family in Arabidopsis and rice. Gene 2008, 407 (1), 1-11.

55. Chuck, G. S.; Tobias, C.; Sun, L.; Kraemer, F.; Li, C.; Dibble, D.; Arora, R.; Bragg, J. N.; Vogel, J. P.; Singh, S.; Simmons, B. A.; Pauly, M.; Hake, S., Overexpression of the maize <em $>$ Corngrass $1</$ em $>$ microRNA prevents flowering, improves digestibility, and increases starch content of switchgrass. Proceedings of the National Academy of Sciences 2011, 108 (42), 17550-17555.

56. Xing, S.; Salinas, M.; Höhmann, S.; Berndtgen, R.; Huijser, P., miR156-Targeted and Nontargeted SBP-Box Transcription Factors Act in Concert to Secure Male Fertility in Arabidopsis. The Plant Cell 2010, 22 (12), 3935-3950.

57. Park, W.; Li, J.; Song, R.; Messing, J.; Chen, X., CARPEL FACTORY, a Dicer Homolog, and HEN1, a Novel Protein, Act in microRNA Metabolism in Arabidopsis thaliana. Current Biology 2002, 12 (17), 1484-1495.

58. Lauter, N.; Kampani, A.; Carlson, S.; Goebel, M.; Moose, S. P., microRNA172 down-regulates glossy15 to promote vegetative phase change in maize. Proceedings of the National Academy of Sciences of the United States of America 2005, 102 (26), $9412-9417$. 
59. Aukerman, M. J.; Sakai, H., Regulation of Flowering Time and Floral Organ Identity by a MicroRNA and Its APETALA2 Like Target Genes. The Plant Cell 2003, 15 (11), 2730-2741.

60. Chen, X., A MicroRNA as a Translational Repressor of APETALA2 in Arabidopsis Flower Development. Science 2004, 303 (5666), 2022-2025.

61. Jung, J.-H.; Seo, Y.-H.; Seo, P. J.; Reyes, J. L.; Yun, J.; Chua, N.-H.; Park, C.-M., The GIGANTEA-Regulated MicroRNA172 Mediates Photoperiodic Flowering Independent of CONSTANS in Arabidopsis. The Plant Cell 2007, 19 (9), $2736-2748$.

62. Huijser, P.; Schmid, M., The control of developmental phase transitions in plants. Development 2011, 138 (19), $4117-4129$.

63. Yan, Z.; Hossain, M. S.; Wang, J.; Valdés-López, O.; Liang, Y.; Libault, M.; Qiu, L.; Stacey, G., miR172 Regulates Soybean Nodulation. Molecular Plant-Microbe Interactions ${ }^{\circledR}$ 2013, 26 (12), 1371-1377.

64. Köhler, C.; Wolff, P.; Spillane, C., Epigenetic Mechanisms Underlying Genomic Imprinting in Plants. Annual Review of Plant Biology 2012, 63 (1), 331-352.

65. Derkacheva, M.; Hennig, L., Variations on a theme: Polycomb group proteins in plants. Journal of Experimental Botany 2013, 65 (10), 2769-2784.

66. Kim, D.-H.; Sung, S., Genetic and epigenetic mechanisms underlying vernalization. The arabidopsis book 2014, 12 , e0171-e0171.

67. Goodrich, J.; Puangsomlee, P.; Martin, M.; Long, D.; Meyerowitz, E. M.; Coupland, G., A Polycomb-group gene regulates homeotic gene expression in Arabidopsis. Nature 1997, 386 (6620), 44-51.

68. Zhang, X.; Clarenz, O.; Cokus, S.; Bernatavichute, Y. V.; Pellegrini, M.; Goodrich, J.; Jacobsen, S. E., Whole-Genome Analysis of Histone H3 Lysine 27 Trimethylation in Arabidopsis. PLOS Biology 2007, 5 (5), e129.

69. Lafos, M.; Kroll, P.; Hohenstatt, M. L.; Thorpe, F. L.; Clarenz, O.; Schubert, D., Dynamic Regulation of H3K27 Trimethylation during Arabidopsis Differentiation. PLOS Genetics 2011, 7 (4), e1002040.

70. Xu, M.; Leichty, A. R.; Hu, T.; Poethig, R. S., H2A.Z promotes the transcription of MIR156A and MIR156C in Arabidopsis by facilitating the deposition of H3K4me3. Development 2018, 145 (2), dev152868.

71. Nodine, M. D.; Bartel, D. P., MicroRNAs prevent precocious gene expression and enable pattern formation during plant embryogenesis. Genes \& development 2010, 24 (23), 2678-2692.

72. Hackett, W. P., Juvenility, Maturation, and Rejuvenation in Woody Plants. In Horticultural Reviews, 1985; pp 109-155.

73. Poethig, R. S., Chapter Five - Vegetative Phase Change and Shoot Maturation in Plants. In Current Topics in Developmental Biology, Rougvie, A. E.; O'Connor, M. B., Eds. Academic Press: 2013; Vol. 105, pp 125-152.

74. Strable, J.; Borsuk, L.; Nettleton, D.; Schnable, P. S.; Irish, E. E., Microarray analysis of vegetative phase change in maize. The Plant Journal 2008, 56 (6), 1045-1057.

75. Mirouze, M.; Paszkowski, J., Epigenetic contribution to stress adaptation in plants. Current Opinion in Plant Biology 2011, 14 (3), 267-274.

76. Cui, L.-G.; Shan, J.-X.; hi, M.; Gao, J.-P.; Lin, H.-X., The miR156-SPL9-DFR pathway coordinates the relationship between development and abiotic stress tolerance in plants. The Plant Journal 2014, 80 (6), 1108-1117.

77. Hsieh, L.-C.; Lin, S.-I.; Shih, A. C.-C.; Chen, J.-W.; Lin, W.-Y.; Tseng, C.-Y.; Li, W.-H.; Chiou, T.-J., Uncovering small RNAmediated responses to phosphate deficiency in Arabidopsis by deep sequencing. Plant physiology 2009, 151 (4), $2120-2132$.

78. Dotto, M.; Gómez, M. S.; Soto, M. S.; Casati, P., UV-B radiation delays flowering time through changes in the PRC2 complex activity and miR156 levels in Arabidopsis thaliana. Plant, Cell \& Environment 2018, 41 (6), 1394-1406.

79. May, P.; Liao, W.; Wu, Y.; Shuai, B.; Richard McCombie, W.; Zhang, M. Q.; Liu, Q. A., The effects of carbon dioxide and temperature on microRNA expression in Arabidopsis development. Nature Communications 2013, 4 (1), 2145.

80. Stief, A.; Altmann, S.; Hoffmann, K.; Pant, B. D.; Scheible, W.-R.; Bäurle, I., Arabidopsis miR156 Regulates Tolerance to Recurring Environmental Stress through SPL Transcription Factors. The Plant Cell 2014, 26 (4), 1792-1807.

81. Lavorel, S.; Lepart, J.; Debussche, M.; Lebreton, J.; Beffy, J., Small scale disturbances and the maintenance of species diversity in Mediterranean old fields. Oikos 1994, 70, 455-473.

82. Burrows, G. E., Epicormic strand structure in Angophora, Eucalyptus and Lophostemon (Myrtaceae) - implications for fire resistance and recovery. New Phytologist 2002, 153 (1), 111-131.

83. Pausas, J. G.; Lamont, B. B.; Paula, S.; Appezzato-da-Glória, B.; Fidelis, A., Unearthing belowground bud banks in fire-prone ecosystems. New Phytol 2018, 217 (4), 1435-1448.

84. Wiltshire, R.; Reid, J. In The pattern of juvenility within Eucalyptus tenuiramis Miq. saplings, Mass production technology for genetically improved fast growing forest tree species. AFOCEL-IUFRO Symposium, 1992.

85. Meier, A. R.; Saunders, M. R.; Michler, C. H., Epicormic buds in trees: a review of bud establishment, development and dormancy release. Tree Physiology 2012, 32 (5), 565-584.

86. Zhang, S.-D.; Ling, L.-Z.; Zhang, Q.-F.; Xu, J.-D.; Cheng, L., Evolutionary Comparison of Two Combinatorial Regulators of SBPBox Genes, MiR156 and MiR529, in Plants. PLOS ONE 2015, 10 (4), e0124621.

87. Barrera-Rojas, C. H.; Rocha, G. H. B.; Polverari, L.; Pinheiro Brito, D. A.; Batista, D. S.; Notini, M. M.; da Cruz, A. C. F.; Morea, E. G. O.; Sabatini, S.; Otoni, W. C.; Nogueira, F. T. S., miR156-targeted SPL10 controls Arabidopsis root meristem activity and root-derived de novo shoot regeneration via cytokinin responses. J Exp Bot 2020, 71 (3), 934-950.

88. Park, J.-Y.; Kim, H.; Lee, I., Comparative analysis of molecular and physiological traits between perennial Arabis alpina Pajares and annual Arabidopsis thaliana Sy-0. Scientific Reports 2017, 7 (1), 13348. 